J. Dairy Sci. 99:5573-5585

http://dx.doi.org/10.3168/jds.2015-10633

(C) American Dairy Science Association ${ }^{\circledR}, 2016$.

\title{
A prospective exploration of farm, farmer, and animal characteristics in human-animal relationships: An epidemiological survey
}

\author{
Alice de Boyer des Roches, ${ }^{*} \dagger^{1}$ Isabelle Veissier, ${ }^{*} \dagger$ Xavier Boivin, ${ }^{*} \dagger$ Emmanuelle Gilot-Fromont, $₫ \S$ \\ and Luc Mounier*† \\ *Université de Lyon, VetAgro Sup, UMR1213 Herbivores, F-69280, Marcy l'Etoile, France \\ †INRA, UMR1213 Herbivores, F-63122 Saint-Genès-Champanelle, France \\ fUniversité de Lyon, VetAgro Sup, F-69280 Marcy l'Etoile, France \\ §Université de Lyon, Université Lyon 1-UMR CNRS 5558-LBBE, F-69622 Villeurbanne, France
}

\section{ABSTRACT}

Human-animal relationships are essential for dairy farming. They affect work comfort and efficiency, as well as milk production. A poor human-animal relationship can result in stress and accidents to both animals and caretakers and needs to be improved. However, many studies have demonstrated the multifactoriality of these relationships. We aimed at assessing the relative importance of the various factors expected to be associated with poor human-animal relationships. On 118 dairy farms, we applied a standardized avoidance distance test to cows at the feeding rack. The sample of farms covered a wide range of situations: lowland versus highland, small versus medium size farms, cubicles versus deep-bedded systems, milking parlor versus automatic milking systems, and Holstein versus Montbéliarde breeds. We used Poisson regression to analyze the links between the number of cows that accepted being touched, and farm characteristics, animals, management, and farmers' attitudes. A multivariate analysis yielded a final model that explained $32.7 \%$ of the variability between farms. Calving conditions ("Main calving location" and "Cleaning or adding litter after calving") accounted for a significant part of the variability observed (respectively 25.8 and $13.6 \%$ of variability explained by the model, SSB). Fewer cows accepted being touched on farms where the main calving location was in the barn, and where farmers cleaned or added litter after calving. The proportion of cows that accepted being touched increased with the proportion of lean cows in the herd (18.8\%), with worker/cow ratio on the farm $(11.7 \%)$, when farmers considered "health" or "human-cow relationships" as most impor-

Received November 12, 2015.

Accepted March 3, 2016.

${ }^{1}$ Corresponding author: alice.deboyerdesroches@vetagro-sup.fr tant issues for farm success (10.4\%), and with farmers' years of experience (10.8\%). Farmers with more negative behavioral attitudes toward cows had a lower proportion of cows that accepted being touched (8.9\%). In conclusion, the human-animal relationship was not found to be associated with farm characteristics (e.g., housing or milking system) but varied with farmers' attitudes and management. We confirm that cows' fear of people is linked to negative attitudes displayed by caretakers toward cows, and is reduced in farms where several caretakers are present. Our study also suggests further exploring the key role of factors linked to calving conditions, as cows are more likely to be afraid of people when disturbed at calving.

Key words: human-animal relationships, animal welfare, dairy cow, farmer's attitude

\section{INTRODUCTION}

In most farming conditions, animals are in contact with humans, so human-animal relationships are essential for farmers and other stakeholders. In the dairy industry, poor human-animal relationships result in low work comfort and efficiency, are associated with reduced milk production, and can result in accidents to both animals and caretakers (Rushen et al., 1999; Hemsworth and Boivin, 2011; Kallioniemi et al., 2011). Good human-animal relationships are also essential for animal welfare because they affect animals' emotions, such a fear during rough handling. The current intensification of dairy systems in Western countries, associated with larger herds and less human contacts, may even worsen human-cattle relationships if the only contacts are aversive (Waiblinger and Menke, 1999).

The human-animal relationship is defined as the mutual perception of the animal and the human, reflected in their mutual behaviors (Waiblinger et al., 2006). Several factors are associated with variations in humananimal relationships at individual and herd levels (European Food Safety Authority, 2009). Cattle's reactions 
to humans depend on their previous experiences with humans (Seabrook, 1984; Boivin et al., 1998; Breuer et al., 2000; Hemsworth et al., 2000) and especially on the behavior of caretakers when they interact with animals (Hemsworth and Coleman, 2010). The behavior of caretakers is strongly influenced by their attitudes. As defined by Eagly and Chaiken (1993), an attitude is a "psychological tendency that is expressed by evaluating a particular entity with some degree of favor or disfavor." Attitudes can be cognitive (beliefs about animals, e.g., one can believe that cows are dangerous) or behavioral (tendency to behave in a particular way, e.g., some caretaker may consider that animals need to be handled gently), and are generally linked to job satisfaction (the degree of comfort one feels in different tasks; Hemsworth and Coleman, 2010). Attitudes are assessed through interviews and questionnaires (e.g., a behavioral attitude is often assessed by asking how frequently someone produces a given behavior; Hemsworth and Coleman, 2010). Farmers' behavior depends also on gender, with women showing more positive behavior than men (Lensink et al., 2000). Beside the type of interactions with the animal, the time at which they occur is essential. Handling is determining for humananimal relationships at 3 periods: early life (Jago et al., 1999; Probst et al., 2012; Schütz et al., 2012), weaning (Boivin et al., 1992; Fukasawa, 2012), and parturition (Hemsworth et al., 1989b).

The animals themselves have an effect on their relation with humans. More specifically, genetic factors seem to play a key role. Animals' reactivity is inheritable (Grandin and Deesing, 1998), and large differences are present both between dairy and beef breeds (Murphey et al., 1980, 1981), and between individuals within a beef cattle breed (Haskell et al., 2014). However, to date, no difference in the human-animal relationships has been reported among dairy breeds (Waiblinger et al., 2003), but this last study did not include the Holstein breed. The age of animals can also affect human-animal relationships, but with strong variations between dairy farms, the easiest cows to approach are either the youngest or the oldest (Waiblinger et al., 2003). The health status of animals may also affect their responses to humans: lame cows are easier to approach, whereas the opposite is observed in cows with mastitis (Mülleder et al., 2003; Ivemeyer et al., 2011). Some production indicators such as total milk yield, milk fat, and milk proteins over lactation are associated with human-animal relationships (Breuer et al., 2000; European Food Safety Authority, 2009), but to date, the association between the nutritional status of dairy cows and human-animal relationships has not been studied. Finally, the social context of animals within the group is also linked to human-animal relationships: the higher the cohesion in the group as shown by frequent positive encounters between animals (such as licking) and rare aggressions, the more readily the animals approach humans (Waiblinger et al., 2003).

Several authors argue that farm characteristics and the way animals are managed affect their relation to humans (Boivin et al., 1994). Grandin (2010) highlights the importance of handling facilities for interventions on cattle on subsequent cattle stress during handling. Other factors such as herd size and work organization can affect caretaker behavior (Waiblinger and Menke, 1999; Lensink et al., 2000; Seabrook, 2001; Hemsworth and Coleman, 2010) and in turn the human-animal relationships. For instance, the larger the farm, the less time is spent with the cows, and the more difficult cows are to approach (Waiblinger and Menke, 1999; Waiblinger et al., 2003).

However, the respective roles of farm characteristics, animals, management, and farmers' attitudes in human-animal relationships remain to be disentangled. The aim of the present epidemiological study was to estimate to what extent these factors are statistically associated with variation in human-dairy cow relationships, assessed through avoidance reactions of cows. Such information is crucial to develop intervention strategies in dairy farms and to improve human-animal relationships and safety of both humans and animals. We chose an epidemiological approach to take full account of the diversity of the situations.

\section{MATERIALS AND METHODS}

A total of 118 commercial dairy farms were visited in 2 French regions (lowlands in Western France - Brittany and Pays de Loire - versus highlands in central and eastern France-Auvergne and Rhône-Alpes). All the farms were family-run, had loose-housing systems (cubicles or deep-bedding barns), and used a milking parlor or an automatic milking system (AMS). All the farms belonged to a milk control organization. Herd size ranged from 21 to 120 dairy cows, and cows were of Montbéliarde (French dual-purpose breed) or Holstein breeds. The farms had been selected at random from exhaustive, anonymous lists provided by the French Health Prevention Group ("Groupement de defense sanitaire"). Random sampling was performed using R 2.15.2 software (R Development Core Team, 2009). Each farm was visited once. The organization of the farm visit followed the Welfare Quality protocol (Welfare Quality, 2009). Five observers carried out the visits. They had been trained previously by an associate from the Welfare Quality project. During training 
on 4 farms, observers' results were compared with each other's and against reference values to ensure reproducibility between observers, and accuracy.

\section{Avoidance Testing at the Feeding Rack}

In Welfare Quality, the measure chosen to assess human-animal relationship is cow avoidance reaction at the feeding rack. This method was chosen because the results are closely correlated with other measures of cows' fear reaction such as passing and touching a lying animal and walking through the herd and touching animals: it varies with previous experience of animals with humans, had good intra- and inter-observer reliability, shows good repeatability of the animal's reaction to different people and a good stability over time, and can easily be performed for routine on-farm assessments (Waiblinger et al., 2003; Winckler et al., 2007; Windschnurer et al., 2008). We applied the Welfare Quality method both for sampling method and behavioral test. On each farm, only a sample of animals was tested. The size of the sample was defined so as to be representative of the whole group of animals: if 30 or fewer lactating cows were present in a herd, all the animals were tested; otherwise 75 to $45 \%$ of cows were randomly chosen, the proportion decreasing with the size of the herd (e.g., 30 cows out of 44, 54 cows out of 120 ; Windschnurer et al., 2009). Once the sample size for a farm was decided, the animals were selected at random. The cows were tested at the feeding rack, when all the cows were back in the barn after morning milking. The observer stood at a distance of $2 \mathrm{~m}$ in front of the cow to be tested, making sure that the cow was paying attention (not foraging), and noted the individual cow number (ear tag number). The observer then approached the cow at a speed of $60 \mathrm{~cm} / \mathrm{s}$ with an arm held overhand at an angle of $45^{\circ}$ from the body and looking at the cow's muzzle. The observer stopped walking when the cow showed a sign of withdrawal (moved back, turned its head to the side, or pulled back its head), or when the cow could be touched on its muzzle. On each farm, the numbers of cows tested and touched was noted.

\section{Factors Studied}

The selection of explanatory factors was based on results from previous studies (as reported in the Introduction above).

The final list consisted of 48 factors split into 4 categories: factors related to the farm, to the management, to the animals, and to the farmer's attitude (Table 1 ). They were collected during the visit by direct observations, from farm records, or by questioning farmers.
Animal factors were recorded by direct observations or from milking records following the Welfare Quality Protocol (Welfare Quality, 2009). Aggressive interactions (butts and displacements) between cows were recorded by continuous sampling for $1 \mathrm{~h}$ after the avoidance test at the feeding rack. Because the frequencies of butts and displacements were strongly correlated $\left(\mathrm{R}^{2}=0.87, P<0.001\right)$, we kept only the frequency of displacements per cow per hour for further analyses. After observing the social behavior, we assessed the body condition and gait of each cow; we considered the percentage of very lean cows in a herd (score 1 in Welfare Quality) and the percentage of lame cows (score 1 and 2 in Welfare Quality). From milk recordings, we extracted, for each cow, SCC for the last 3 mo before the visit, parity, number of days since calving, and maximum level of production in the first 3 mo of lactation.

Farmers' personal characteristics, job satisfaction, and attitudes toward cows and working with cows were evaluated using a questionnaire built on the basis of previously published work (Breuer et al., 2000; Lensink et al., 2000; Waiblinger et al., 2002; Mounier et al., 2006). We did not observe farmers' behavior with cows because of time constraints and more importantly because behavior can vary from one day to another or due to the presence of the observer. We rather focus on attitudes, which, according to the theory of reasoned action, are supposed to reflect the farmer's tendency to behave in a certain way (Ajzen and Fishbein, 1980). Hence, we used indicators of behavioral attitudes because they are good predictors of farmers' average behavior toward animals in different species including cattle (Hemsworth et al., 1989a; Lensink et al., 2000; Waiblinger et al., 2002; Hemsworth and Coleman, 2010). We chose to limit the questionnaire to 32 questions subdivided into 5 parts: 2 questions on gender and years of experience working with cows; one question on the issue farmers considered the most important for farm success; 8 questions on job satisfaction (in the form of "How much do you like $x$ ?" where $x$ was an action such as "cleaning the barn" or "being with dairy cows"); 8 questions on cognitive attitudes (in the form of "Do you agree with $x$ ?" where $x$ was a statement such as "cows are sensitive to the contact with farmer" or "cows have a good memory"); and 13 questions on behavioral attitudes (in the form of "how often do you $x$ ?" where $x$ was an action such as "talk to cows" or "yell at cows"). The responses to questions on job satisfaction and attitudes were scored on a 1 to 10 scale where 1 corresponded to "I do not like $x " / " I$ do not agree with $x " / " I$ never do $x$," whereas 10 corresponded to "I like $x$ very much")/"I completely agree with $x "$ )/"I always do $x$ " (for job satisfaction/ cognitive attitudes/behavioral attitude, respectively). 
Table 1. Factors studied: categories, factors, and levels

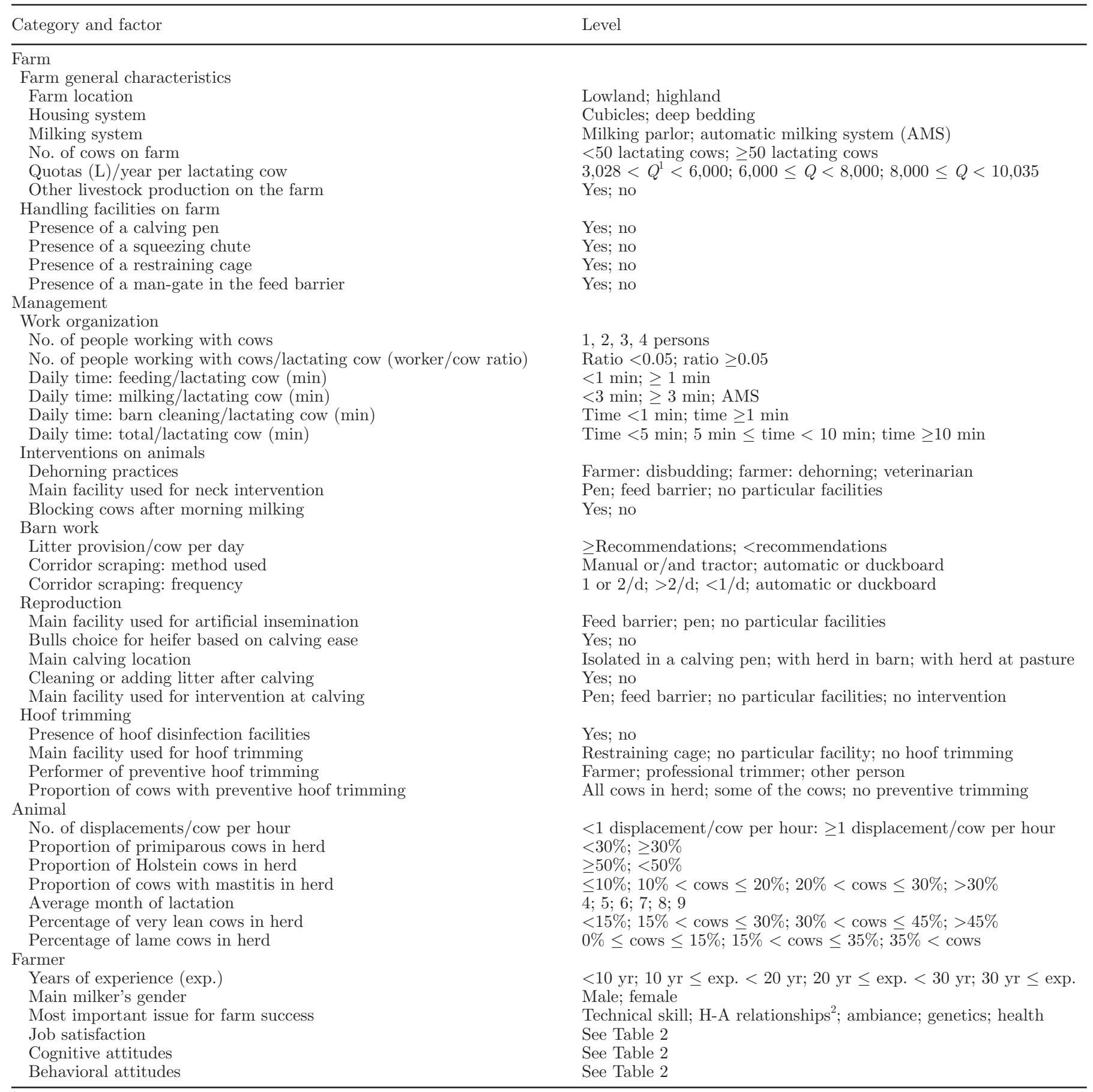

${ }^{1} Q=$ quota.

${ }^{2} \mathrm{H}-\mathrm{A}$ relationships = human-animal relationships.

The farms were managed by 1 to 4 persons. If the farm was managed by more than one person, the questionnaire was filled in by the person working the most with the cows, called the farmer in the present paper. This person was responsible of the daily management of the cows (food distribution, barn cleaning, cow milking).

\section{Statistical Analyses}

In all analyses, the observational unit was the farm.

First, to summarize the data on farmers' attitudes, we ran principal component analyses (PCA) for each category of attitudes (job satisfaction, cognitive and 
behavioral attitudes). We focused on axes that had an eigenvalue higher than 1 . To interpret these axes, we took into account variables with a contribution of absolute value higher than 0.3 . We used the 1 st and 2 nd axis synthetic variable to summarize attitudes.

We then modeled the number of cows touched during the avoidance test per farm with a Poisson generalized linear model (GLM). Poisson regression let us adjust the number of cows touched during the test per farm for sample size (i.e., number of cows tested per farm) by using the total number of cows tested per farm as an offset variable (Dohoo et al., 2009). To analyze the links between the 48 factors studied and the number of cows touched during the avoidance test, we first used univariate GLM. The factors with a probability of effect of 0.05 or less were kept to build a multivariate full model. The full model was then simplified by backward elimination according to the Akaike information criterion (AIC; Akaike, 1973). The simplification was stopped when no factor that would decrease the AIC value could be removed (Burnham et al., 2011). The chosen model was analyzed using likelihood ratio tests for the effect of factors and Wald tests for the contrast between modalities. Finally, among models with close AIC values $(\Delta<2)$, we selected the most parsimonious (i.e., the model with the fewest parameters). The normal distribution of residuals was checked with a Shapiro-Wilk test, and the homogeneity of variance was checked with a Levene test.

Analyses were performed using the software R 2.15.2 (R Development Core Team, 2009). Package ade4 was used for PCA and package Mass for model simplification. We will comment on results for which $P \leq 0.05$.

\section{RESULTS}

Details of farm, management, animal and farmer characteristics of the 118 farms and results of univariate analysis are presented in Supplemental Table S1 (http://dx.doi.org/10.3168/jds.2015-10633).

The 118 farms had a median herd size of 54.4 lactating cows (minimum, 23; maximum, 125), and we tested a median of 36.5 (minimum, 23; maximum, 60) cows per farm. On 18 farms ( $15.3 \%$ of the farms), no cow accepted being touched when approached at the feeding rack. On 64 farms (54\% of the farms), fewer than $10 \%$ of the cows could be touched. The median was $9.10 \%$ of the cows touched by the observer (minimum, $0.0 \%$; maximum, $35.0 \%$; Figure 1). No farm was found to mistreat animals: even on the 18 farms where no cows could be touched, cows could still be approached at less than $2 \mathrm{~m}$ and these farms had a median score of 33.3 (minimum, 21.8; maximum, 56.3) on the 0 to 100 scale defined by Welfare Quality, which is higher than 20 , the limit for acceptability.

\section{Principal Component Analyses on Farmers' Attitudes}

The results of PCA analyses are detailed in Table 2 . For job satisfaction, axes 1 and 2 explained 28.7 and $15.4 \%$ of the total variance, and they can be summarized as an axis for satisfaction during "barn work" (axis 1, the farmer enjoys adding litter in the barn, cleaning the barn, milking cows, and milking constraints) and satisfaction during "work with animals" (axis 2, the farmer enjoys being with dairy cows, taking care of calves, the farmer dislikes sending a cow to the slaughterhouse). On both axes, the higher the score, the higher the level of satisfaction. For cognitive attitudes, axes 1 and 2 explained 32.0 and $14.9 \%$ of the total variance, and they can be summarized by "belief in cows having cognitive capacities" (axis 1, cows are sensitive to contact with the farmer, cows are sensitive to pain, cows have a good memory, and cows recognize the farmer, with high scores corresponding to the belief that cows have high cognitive capacities), and "belief in cows being more sensitive to barn comfort versus persons" (axis 2 , with high values correspond to beliefs that cows are more sensitive to the quality of the walking floor, and of the resting floor than to the contact with people other than the farmer). For behavioral attitudes, axes 1 and 2 explained 20.0 and $14.3 \%$ of the total variance and can be summarized by "gentle behaviors" (axis 1, the farmer warns cows before preparing the udder for milking, strokes cows, lets calves suck his/her fingers, lets cows smell him/her, and talks to cows), with high values corresponding to frequent gentle behaviors, and "negative behaviors" (axis 2, the farmer kicks cows, hits them on the muzzle, yells at cows, hits cows with a stick, with high values corresponding to frequent negative behaviors).

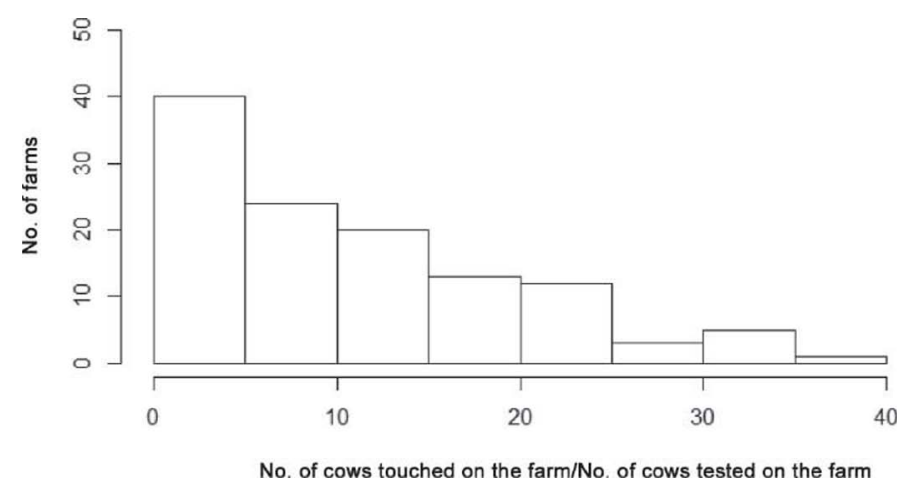

Figure 1. Distribution of the proportion of cows touched during the avoidance distance test in 118 dairy farms. 


\section{Univariate Analyses}

A total of 19 factors had $P<0.05$ in the univariate analyses (Table 3 ).

Farms with a higher proportion of cows touched were observed when cattle were the only animal production species on the farm $(P=0.007)$, when the milking system was an AMS $(P=0.023)$, when cows produced more than $6,000 \mathrm{~L}$ of milk per year per cow on average $(P=0.027)$, when the level of aggression among cows was low $(P=0.011)$, when cows were at their 4th month of lactation on average $(P=0.016)$, when less than $30 \%$ of cows had mastitis in the herd $(P=$ $0.005)$, when more than $45 \%(P=0.0023)$ or less than $30 \%(P=0.015)$ of very lean cows were present in the herd, when more than 3 people worked with cows
$(P<0.001)$, when more than one person was working with 20 cows $(P<0.001)$, when the time spent milking per cow was longer than 3 min $(P=0.002)$ or when an AMS was present $(P<0.001)$, when calving took place in pasture $(P=0.026)$ or in a separate pen $(P<0.001)$, when farmer reported not often cleaning the calving location/adding litter after calving $(P<$ $0.001)$, when no hoof disinfection facilities were present $(P=0.024)$, when the farmer had more than $10 \mathrm{yr}$ of experience $(P \leq 0.029$ for the 3 modalities), when the main milker was a woman $(P=0.011)$, when the issue farmers considered the most important for farm success was "health" $(P=0.028)$, when farmers reported enjoying "barn work" $(P=0.017)$ and "work with animals" $(P=0.007)$, and when they reported seldom behaving negatively toward their animals $(P=0.007)$.

Table 2. Principal component analyses (PCA) on attitudes of farmers: PCA on job satisfaction, PCA on cognitive attitudes, and PCA on behavioral attitudes: for each principal component considered we give the eigenvalue, proportion of variance explained by the component, and contribution of each variable to the component $^{1}$

\begin{tabular}{|c|c|c|}
\hline PCA & Component 1 & Component 2 \\
\hline \multicolumn{3}{|l|}{ Farmers' job satisfaction } \\
\hline Eigenvalue & 2.30 & 1.23 \\
\hline Proportion of total variance explained by component (\%) & 28.7 & 15.4 \\
\hline \multicolumn{3}{|l|}{ Contribution of each variable to components: } \\
\hline Farmer enjoys being with dairy cows & 0.25 & 0.46 \\
\hline Farmer enjoys adding litter in the barn & 0.51 & -0.08 \\
\hline Farmer enjoys cleaning the barn & 0.44 & -0.12 \\
\hline Farmer enjoys milking cows & 0.35 & -0.15 \\
\hline Farmer enjoys taking care of calves & 0.24 & 0.53 \\
\hline Farmer enjoys fetching cows for milking & 0.27 & 0.07 \\
\hline Farmer enjoys milking constraints & 0.47 & -0.19 \\
\hline Farmer dislikes sending a cow to slaughterhouse & 0.04 & 0.65 \\
\hline \multicolumn{3}{|l|}{ Farmers' cognitive attitudes } \\
\hline Eigenvalue & 2.56 & 1.19 \\
\hline Proportion of total variance explained by component (\%) & 32.0 & 14.9 \\
\hline \multicolumn{3}{|l|}{ Contribution of each variable to components: } \\
\hline Cows are sensitive to the quality of walking floor & 0.25 & 0.63 \\
\hline Cows are sensitive to the quality of resting floor & 0.35 & 0.47 \\
\hline Cows are sensitive to schedules & 0.23 & -0.03 \\
\hline Cows are sensitive to contact with the farmer & 0.47 & -0.08 \\
\hline Cows are sensitive to contact with people other than the farmer & 0.22 & -0.53 \\
\hline Cows are sensitive to pain & 0.43 & -0.04 \\
\hline Cows have a good memory & 0.43 & -0.08 \\
\hline Cows recognize the farmer & 0.35 & -0.29 \\
\hline \multicolumn{3}{|l|}{ Farmers' behavioral attitudes } \\
\hline Eigenvalue & 2.41 & 1.71 \\
\hline Proportion of total variance explained by component (\%) & 20.0 & 14.3 \\
\hline \multicolumn{3}{|l|}{ Contribution of each variable to components: } \\
\hline Farmer gives the cows a name & 0.14 & -0.24 \\
\hline Farmer warns cows before preparing udder for milking & 0.37 & -0.22 \\
\hline Farmer strokes cows & 0.50 & -0.25 \\
\hline Farmer lets calves suck his/her fingers & 0.36 & 0.21 \\
\hline Farmer lets cows smell him/her & 0.46 & 0.04 \\
\hline Farmer kicks cows & 0.14 & 0.35 \\
\hline Farmer hits cows on the muzzle & 0.08 & 0.31 \\
\hline Farmer yells at cows & 0.17 & 0.41 \\
\hline Farmer talks to cows & 0.35 & -0.13 \\
\hline Farmer hits the cows with a stick & 0.04 & 0.58 \\
\hline Farmer grabs the calf's ear to handle it & 0.22 & -0.05 \\
\hline Farmer is reluctant to cull his favorite cows & 0.18 & 0.21 \\
\hline
\end{tabular}

${ }^{1}$ Bold represents variables that contribute most to the component. 


\section{Multivariate Analysis}

Among the 19 significant factors revealed by the univariate analyses, only 7 were kept in the final multivariate model (Table 4). This model explained $32.7 \%$ of the variability between farms (likelihood ratio test, $P<0.001)$. Residuals distribution did not differ from a normal distribution (Shapiro-Wilk normality test, $W=$ $0.99, P=0.59)$ and variance was homogeneous across groups (Levene's test, $P>0.05$ for all factors). The final model had an AIC of 520.69.

Main calving location contributed to $25.8 \%$ of the variability explained by the model (i.e., sum of square between classes, SSB), with more cows touched when calving took place in pasture $(P=0.001)$ or in a separate pen $(P<0.001)$. Percentage of very lean cows in the herd contributed to $18.8 \%$ of the SSB, with more cows touched when the percentage of very lean cows lay between 15 and $30 \%(P=0.025)$ or above $45 \%(P=0.002)$. Cleaning or adding litter after calving contributed to $13.6 \%$ of the SSB, with more cows touched when the farmer reported not often cleaning the calving location or adding litter after calving ( $P$ $<0.001)$. The number of persons working with cows/ lactating cow (worker/cow ratio) contributed to $11.7 \%$ of the SSB: more cows were touched when more than one person was working for 20 cows $(P=0.009)$. Farmers' experience contributed to $10.8 \%$ of SSB: more cows were touched when the farmer had more than $10 \mathrm{yr}$ of experience $(P<0.05$ in all cases $)$. The issue identified as most important for farm success contributed to $10.4 \%$ of the SSB, with more cows touched when farmers considered "human-animal relationship" ( $P=$ $0.047)$ or "health" $(P<0.001)$ as most important for farm success. Farmers' negative behavioral attitude toward cows contributed to $8.9 \%$ of the SSB: more cows were touched on farms where the farmer reported seldom or never behaving negatively toward cows $(P<$ 0.001).

\section{DISCUSSION}

The scientific literature on factors influencing humancow relationships is very broad, but generally only 1 or 2 factors are explored at a time (e.g., type of interactions with the animal, herd size, animals' health status, farm characteristics, and so on). To our knowledge, this epidemiological study is the first to give a big picture, taking into account all factors (farm characteristics, animals, management, and farmers' attitudes) at the same time. It gives an insight into their relative association with the human-animal relationship, assessed by the percentage of cows touched when approached at the feeding rack in dairy farms where cows are loose- housed. We adopted a cross-cutting epidemiological approach. The findings must therefore be considered with caution: they show association between several factors and human-animal relationships. These associations should not be considered as cause-effects links but raise hypotheses for such links to be tested in controlled studies.

We recorded cows' avoidance reaction at the feeding rack to assess the human-animal relationship. This test, which can be easily performed on farms, was chosen because its validity had been proven by previous studies: avoidance reaction at the feeding rack correlates highly with avoidance distance in the pen (correlation coefficients, 0.82; Windschnurer et al., 2008) and thus seems not to be affected by animal hunger, it is also moderately correlated with reactions of the cows to a human walking through a pen and touching cows standing or lying (correlation coefficients, 0.59 and 0.56; Windschnurer et al., 2008). In addition, the cow' reaction is similar to different unknown people (between experimenter repeatability: correlation coefficient, 0.87 ; Windschnurer et al., 2008, 2009), and when retested by the same person (test-retest repeatability: correlation coefficient, 0.87; Windschnurer et al., 2008, 2009). This test also showed good stability over time on a 5-mo period (Winckler et al., 2007). The validity of this test was confirmed in our study since the results obtained varied with the farmer's attitude (see below), a relation that had already been obtained using more sophisticated measurements (Breuer et al., 2000; Waiblinger et al., 2002).

On $54 \%$ of farms, less than $10 \%$ of cows could be touched, and the median percentage of cows that accepted being touched reached $9.10 \%$. This result raises a concern about work comfort and efficiency in dairy farms and about farmers' and animals' day-to-day safety (Rushen et al., 1999). The test used in the present study reflects the "flight zone" of the cow, which varies according to its relation with humans: the smaller the flight zone, the better the human-animal relationship (Waiblinger et al., 2003; Grandin, 2010). Hence, cows accepting human contact are those with very good human-animal relationships. We found only one database and one study published using the same test on dairy farms. The proportion of cows that accepted being touched in our study $(9.10 \%)$ was lower than that in the Welfare Quality database (http://www1. clermont.inra.fr/wq/), which reports a median of $30.3 \%$ of cows accepting being touched in 398 European dairy farms. It was also lower than that of Windschnurer et al. (2008), who reported a median of $36 \%$ in 16 Austrian commercial dairy farms. These differences may come from the small sample (16 farms) in the study of Windschnurer et al. (2008; vs. 118 farms in the present 
Table 3. Coefficients of univariate Poisson regression models ( $Z$-value and $P$-value are stated for Wald tests of contrasts between modality "ref" and other ones) between farm/animal/management/farmer variables and the prevalence of cows touched on a farm adjusted for sample size

\begin{tabular}{|c|c|c|c|c|c|c|}
\hline Category and factor & Level & $\begin{array}{l}\text { No. of } \\
\text { farms }\end{array}$ & $\begin{array}{l}\% \text { of cows } \\
\text { touched } \\
\text { predicted } \\
\text { by model }^{1}\end{array}$ & $\begin{array}{l}95 \% \\
\text { CI }\end{array}$ & $Z$ & $P$-value \\
\hline \multicolumn{7}{|l|}{ Farm } \\
\hline \multirow[t]{2}{*}{ Milking system } & Milking parlor (ref) & 100 & 10.3 & {$[9.31-11.3]$} & & \\
\hline & AMS & 18 & 13.3 & {$[10.9-16.2]$} & 2.27 & 0.023 \\
\hline \multirow[t]{3}{*}{ Quotas (L)/year per lactating cow } & $3,000<P<6,000$ (ref) & 20 & 8.13 & {$[6.16-10.4]$} & & \\
\hline & $6,000 \leq P<8,000$ & 70 & 11.2 & {$[10.0-12.5]$} & 2.21 & 0.027 \\
\hline & $8,000 \leq P<10,035$ & 25 & 11.8 & {$[9.77-14.2]$} & 2.29 & 0.022 \\
\hline \multirow[t]{2}{*}{ Other livestock production on the farm } & Yes (ref) & 63 & 9.60 & {$[8.43-10.9]$} & & \\
\hline & No & 55 & 12.2 & {$[10.7-13.9]$} & 2.66 & 0.007 \\
\hline \multicolumn{7}{|l|}{ Animal } \\
\hline \multirow[t]{2}{*}{ No. of displacements/cow per hour ${ }^{2}$} & $\underset{\text { (ref) }}{\geq 1 \text { displacement/cow per hour }}$ & 86 & 10.0 & {$[8.94-11.2]$} & & \\
\hline & $<1$ displacement/cow per hour & 32 & 12.8 & {$[10.9-14.9]$} & 2.55 & 0.011 \\
\hline \multirow[t]{4}{*}{ Proportion of cows with mastitis in herd ${ }^{2}$} & $10 \%<$ cows $\leq 20 \%($ ref $)$ & 42 & 9.01 & {$[7.61-10.6]$} & & \\
\hline & $\leq 10 \%$ of cows & 16 & 11.2 & {$[8.78-14.1]$} & 1.50 & 0.135 \\
\hline & $>30 \%$ of cows & 20 & 11.4 & {$[9.13-14.0]$} & 1.71 & 0.087 \\
\hline & $20 \%<$ cows $\leq 30 \%$ of cows & 40 & 12.9 & {$[10.6-14.2]$} & 2.78 & 0.005 \\
\hline \multirow[t]{4}{*}{ Average month of lactation } & 5 (ref) - - & 37 & 9.54 & {$[8.00-11.2]$} & & \\
\hline & $\geq 7$ & 18 & 10.5 & {$[8.28-13.2]$} & 0.68 & 0.495 \\
\hline & 6 & 44 & 11.2 & {$[9.61-12.9]$} & 1.38 & 0.167 \\
\hline & 4 & 18 & 13.3 & {$[10.7-16.4]$} & 2.39 & 0.016 \\
\hline \multirow{4}{*}{ Percentage of very lean cows in herd ${ }^{2}$} & $45 \% \geq$ cows $>30 \%($ ref $)$ & 9 & 7.55 & {$[5.01-10.8]$} & & \\
\hline & $15 \%>$ cows & 71 & 9.59 & {$[8.45-10.8]$} & 1.16 & 0.247 \\
\hline & $30 \%>$ cows $>15 \%$ & 22 & 12.8 & {$[10.6-15.4]$} & 2.43 & 0.015 \\
\hline & cows $>45 \%$ & 16 & 14.8 & {$[12.0-17.9]$} & 3.04 & 0.002 \\
\hline \multirow[t]{3}{*}{ Percentage of lame cows in herd ${ }^{2}$} & $15 \%>$ cows $>0 \%($ ref $)$ & 76 & 10.0 & {$[8.89-11.2]$} & & \\
\hline & $35 \%>$ cows $>15 \%$ & 31 & 12.0 & {$[10.1-14.1]$} & 1.75 & 0.079 \\
\hline & cows $>35 \%$ & 11 & 12.8 & {$[9.68-16.4]$} & 1.64 & 0.101 \\
\hline \multicolumn{7}{|l|}{ Management } \\
\hline \multirow[t]{4}{*}{ No. of people working with cows } & 2 persons (ref) & 67 & 10.4 & {$[9.25-11.8]$} & & \\
\hline & 1 person & 27 & 10.5 & [8.61-12.8] & 0.76 & 0.939 \\
\hline & 3 persons & 20 & 10.5 & {$[8.36-12.9]$} & 0.01 & 0.989 \\
\hline & 4 persons & 4 & 19.5 & {$[13.5-27.1]$} & 3.33 & 0.001 \\
\hline \multirow{2}{*}{$\begin{array}{l}\text { No. of people working with cows/lactating } \\
\text { cow } \\
\text { (worker/cow ratio) }\end{array}$} & Ratio <0.05 (ref) & 89 & 9.76 & {$[8.75-10.9]$} & & \\
\hline & Ratio $\geq 0.05$ & 29 & 14.2 & {$[12.0-16.6]$} & 3.78 & $<0.001$ \\
\hline \multirow{3}{*}{ Daily time: milking/lactating cow (min) } & $<3 \min (\mathrm{ref})$ & 28 & 7.74 & {$[6.19-9.54]$} & & \\
\hline & $\geq 3 \min$ & 72 & 11.35 & {$[10.1-12.7]$} & 3.07 & 0.002 \\
\hline & $\overline{\mathrm{A}} \mathrm{MS}$ & 18 & 13.4 & {$[10.9-16.2]$} & 3.64 & 0.003 \\
\hline \multirow[t]{3}{*}{ Main calving location } & Cow with herd, in the barn (ref) & 15 & 7.10 & {$[5.10-9.58]$} & & \\
\hline & Cow with herd, at pasture & 49 & 10.5 & {$[9.07-12.1]$} & 2.22 & 0.027 \\
\hline & Cow isolated in a calving pen & 52 & 12.4 & {$[10.9-13.9]$} & 1.75 & $<0.001$ \\
\hline \multirow[t]{2}{*}{ Cleaning or adding litter after calving } & Yes (ref) & 79 & 9.23 & {$[8.18-10.4]$} & & \\
\hline & No & 39 & 14.0 & {$[12.2-15.9]$} & 4.49 & $<0.001$ \\
\hline Presence of hoof disinfection facilities & Yes (ref) & 38 & 9.26 & {$[7.80-10.9]$} & & \\
\hline & No & 80 & 11.6 & {$[10.4-12.9]$} & 2.27 & 0.024 \\
\hline Farmer & & & & & & \\
\hline Years of experience (exp.) & $<10 \mathrm{yr}$ & 21 & 7.35 & {$[5.59-9.28]$} & & \\
\hline & 20 yr $\leq \exp .<30$ yr & 41 & 10.1 & {$[8.61-11.9]$} & 2.17 & 0.029 \\
\hline & $10 \mathrm{yr} \leq \exp .<20$ yr & 38 & 12.2 & {$[10.5-14.1]$} & 3.46 & $<0.001$ \\
\hline & $30 \mathrm{yr} \leq \exp$ & 18 & 13.6 & {$[11.0-16.6]$} & 3.77 & $<0.001$ \\
\hline Main milker's gender & Male (ref) & 107 & 10.4 & {$[9.4-11.4]$} & & \\
\hline & Female & 11 & 14.6 & {$[11.3-18.3]$} & 2.53 & 0.0114 \\
\hline Issue identified as most important for & Farmer's technical skill (ref) & 74 & 9.83 & {$[8.67-11.0]$} & & \\
\hline farm success & Genetics & 11 & 10.8 & {$[7.85-14.5]$} & 0.61 & 0.543 \\
\hline & Ambiance in the barn & 10 & 11.7 & {$[8.55-15.6]$} & 1.09 & 0.275 \\
\hline & Human-cow relationship & 13 & 12.7 & {$[9.89-16.1]$} & 1.91 & 0.056 \\
\hline & Health & 9 & 13.8 & {$[10.3-18.1]$} & 2.21 & 0.028 \\
\hline $\mathrm{PCA}^{3}$ "job satisfaction": Component 1 & Intercept & & 10.8 & {$[9.87-11.8]$} & & \\
\hline & Component 1 & & +1.07 & & 2.38 & 0.017 \\
\hline PCA "job satisfaction": Component 2 & Intercept & & 10.7 & {$[9.80-11.8]$} & & \\
\hline & Component 2 & & +1.11 & & 2.69 & 0.007 \\
\hline
\end{tabular}


Table 3 (Continued). Coefficients of univariate Poisson regression models ( $Z$-value and $P$-value are stated for Wald tests of contrasts between modality "ref" and other ones) between farm/animal/management/farmer variables and the prevalence of cows touched on a farm adjusted for sample size

\begin{tabular}{|c|c|c|c|c|c|c|}
\hline Category and factor & Level & $\begin{array}{l}\text { No. of } \\
\text { farms }\end{array}$ & $\begin{array}{l}\% \text { of cows } \\
\text { touched } \\
\text { predicted } \\
\text { by model }^{1}\end{array}$ & $\begin{array}{c}95 \% \\
\text { CI }\end{array}$ & $Z$ & $P$-value \\
\hline
\end{tabular}

"Example: if the "milking system" is not "milking parlor" (ref) but automatic milking system (AMS), then the percentage of cows touched reaches $13.3 \%$; compared with reference $(10.3 \%)$, it increased $3 \%$.

${ }^{2}$ Measure of the Welfare Quality protocol.

${ }^{3} \mathrm{PCA}=$ principal component analysis.

study) or from differences in farmers' practices, in the animals themselves, or in farm variables. Our study can help gain a better understanding of such variations.

When considered separately (i.e., in univariate models), factors from all the categories studied [animals (behavior, health, breed, rank of lactation), farm characteristics, farm management, farmers' attitudes] were significantly associated with the proportion of cows touched when approached at the feeding rack. Not all of these factors were kept in the final multivariate model: the information they carried was summarized by factors kept in the final model, owing to confounding effects. For instance, the daily time spent milking cows and the number of people working with cows were

Table 4. Coefficients of the best fitting multivariable Poisson regression model between farm/animal/management/farmer variables and the prevalence of cows touched on a farm adjusted on sample size ( $Z$-value and $P$-value are stated for Wald tests of contrasts between modality "ref" and other ones)

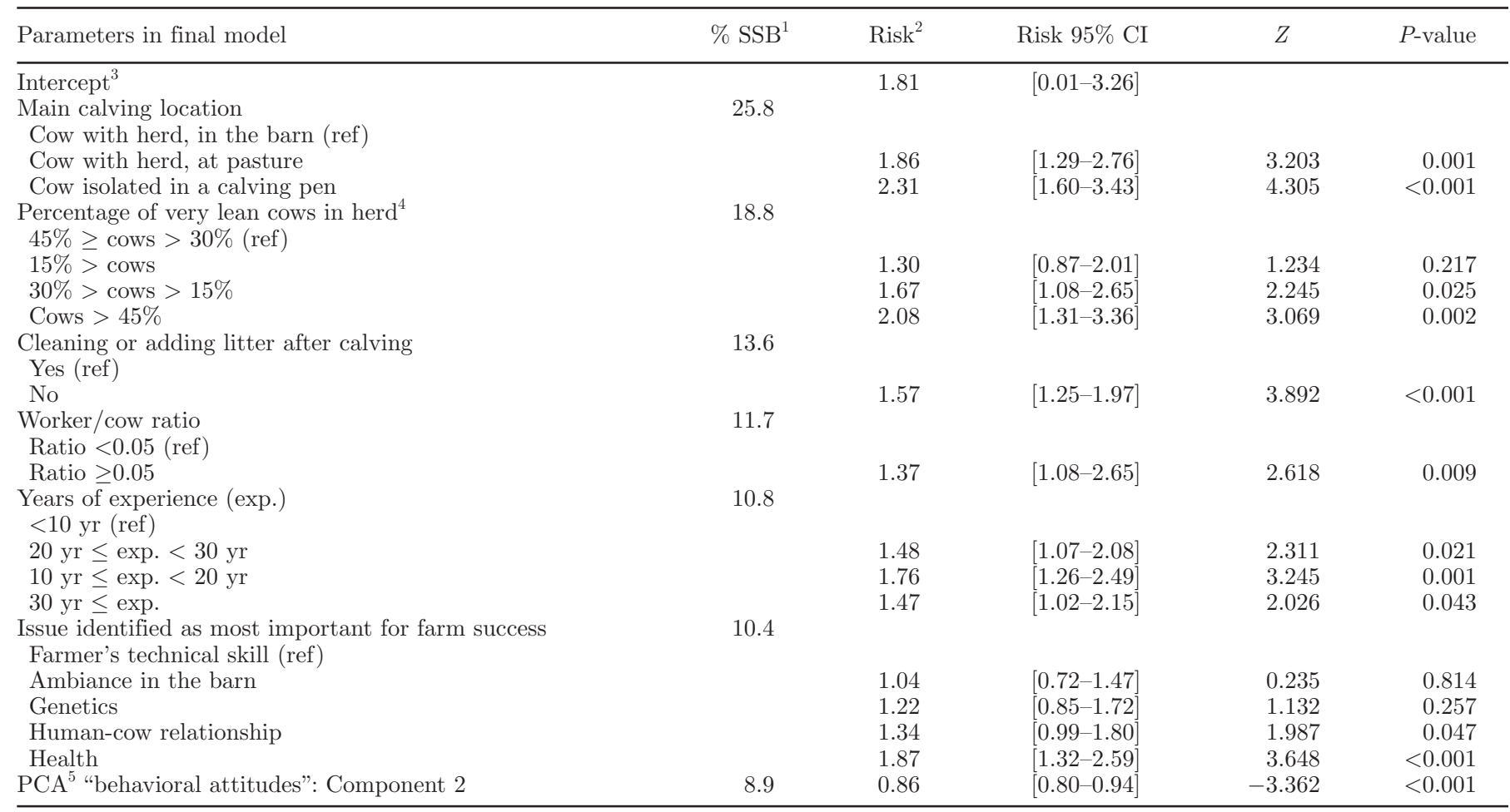

${ }^{1} \mathrm{SSB}$ is the sum of square between classes (i.e., the variability explained by the model).

${ }^{2}$ Example: compared with reference ( $1.81 \%$ of cows touched) if the "percentage of very lean cows in herd" is not " $30 \%<$ cows $\leq 45 \%$ " (ref) but " $<15 \%$," then the percentage of cows touched is multiplied by 1.30: it reaches $2.34 \%$.

${ }^{3}$ Intercept corresponds to the percentage of cows touched predicted by the model (1.81\%) in farms of which characteristics are reference levels (ref) of all factors.

${ }^{4}$ Measure of the Welfare Quality protocol.

${ }^{5} \mathrm{PCA}=$ principal component analysis. 
probably linked to the worker/cows ratio, a factor that was kept in the final model. This suggests that the most important variable for the cow may be the variety of contacts it receives from humans. The originality of our study was thus that it took into account all the factors at the same time, and highlighted the "keystone" factors, (i.e., those most likely to be associated with the animals' response to humans).

In the multivariate model, only 7 factors, belonging to all categories except farm characteristics, were finally found to be related to cows' behavior toward humans. The variability was mostly explained by factors of calving management (39.4\%; location of calving, management of the calving pen), farmer (19.7\%; experience and attitude of the farmer toward cows), animals (18.8\%; animal nutritional status), and worker/cow ratio $(11.7 \%)$.

One of the strongest associations occurred with location and management of calving. A lower proportion of cows were touched in farms where cows calved indoors in the main pen where other cows were kept compared with farms where cows calved in a separate pen or at pasture. Experienced cows need a quiet place to calve (Lidfors et al., 1994; Proudfoot et al., 2014). In cattle, maternal isolation at calving and seclusion of the calf have been suggested to facilitate the establishment of the dam-calf bond because this lowers the disturbance of interactions from other cows (Lidfors et al., 1994). It is also thought to lower the risk of predation on the calf. In the main pen, cows less easily find isolation from other cows or other stimuli, and may have been disturbed more at calving. Alternatively, one could hypothesize that farmers who have a deeper concern for their cows move them to a calving pen when they are indoors and about to calve, and the association with the proportion of cows touched could come from this deeper concern. However, a higher proportion of cows were touched in farms where the farmer reported not cleaning or adding litter after calving, which suggests a lower concern for cows. Surprisingly, previous results from Hemsworth et al. $(1987,1989 b)$ showed that handling primiparous cows around calving eases their later handling during lactation. The difference between our results and those of previous studies could be partially due to the characteristics of close contacts with the person present at calving. In Hemsworth et al. (1987 1989b), the experimenter had smeared fetal fluid from the cow's calf on his hands, the fetal fluids being an important stimulus for the dam's attraction to the calf, whereas this was not the case here. Our results suggest that calving location and management allowing separation from humans and other cows and thus probably more quietness for the cow may be beneficial to cowhuman relationships.
A higher proportion of cows were touched in farms where the farmer had more than $10 \mathrm{yr}$ of experience. No previous study reports an association between farmers' number of years of experience and cattle reactions. However, we hypothesize that experienced farmers are more confident in their contacts with cows, and may be more patient with them, anticipating their reactions to adjust their behavior. We found no link between the number of years of experience the farmers had and their attitudes studied here, but we hypothesize that features such as precise quality of handling and patience toward the animals could allow smoother interactions and in turn lower fear responses of cows to humans.

Finally, our study confirms the association between farmers' behavioral attitudes and human-animal relationships. Farms where farmer had negative behavioral attitudes (reporting kicking cows, hitting them, yelling at them) had a lower proportion of cows touched, a finding already reported in dairy cows (Breuer et al., 2000) and in pigs and poultry (Hemsworth and Boivin, 2011). Farmers' attitudes, farmers' behavior, and cows' reaction to human approach is a loop of association links, each item affecting the next one as well as the previous one: a cow that is frightened by people can react strongly at their approach and this in turn can reinforce a negative attitude toward that cow (Hemsworth and Coleman, 2010). According to Ajzen and Fishbein (1980), attitudes are good predictors of behavior: in the context of human-animal relationship they reflect the frequency and nature of interactions between the farmer and the animals (Waiblinger et al., 2002; Hemsworth and Coleman, 2010). Hence, our results support the fact that cow-human relationships result at least in part from the previous experience of cows in contacts with their caretakers (Hemsworth and Boivin, 2011).

An important factor associated with animal responses to humans was the proportion of very lean cows. When this proportion was high, cows could be more easily touched. Body condition reflects the nutritional status of an animal. In Welfare Quality, "very lean" corresponds to a score of $<2.5$ in the grid of Edmonson et al. (1989), meaning that energy needs are not met by the dietary supply. The avoidance distance test was performed just after morning milking, when cows were highly motivated to eat. Although, the approach text at the feeding rack is correlated with a similar test performed in the pen (that is, when the cow is not feeding; Windschnurer et al., 2008), we could hypothesize that cows with a very low body condition are more motivated to consume feed than to recoil from the experimenter.

The ratio of persons working with cows per lactating cow was more closely associated with the proportion of cows touched than the attitudes of the main caretaker: 
the higher the ratio, the more cows could be touched. This factor in dairy cows' response to humans had not yet been reported. Lensink et al. (2001) observed a lower withdrawal tendency of veal calves (to the passage of an unfamiliar observer and the farmer) when a high number of caretakers worked at the veal unit. This effect could be due to cows being more accustomed to interacting with different people, with a different appearances and gestures, so that through the process of stimulus generalization (Hemsworth and Coleman, 2010), they were less afraid of the experimenter approaching them during the test.

Several factors were expected to be associated with cows' reaction in the test, but were not evidenced by our multivariate model. For instance, handling facilities are of importance for interventions on cattle to lower cattle stress during handling, and promote human safety (Grandin, 2010). The lack of any links between handling facilities and cows' avoidance reaction may be explained by the narrow variation between farms from our sample in handling facilities used for several interventions on dairy cows. Regarding genetic factors, our study provides no evidence of any differences in the human-animal relationships among dairy breeds, as already suggested (Waiblinger et al., 2003; Haskell et al., 2014). This low variability may be because both Holstein and Montbeliarde are dairy breeds: such cows come into contact with humans twice daily for milking. Besides production level traits, their selection might therefore have included behavioral traits such as temperament to ensure handling efficiency and human safety (Haskell et al., 2014).

The final model explained only $32.7 \%$ of the variability between farms. This moderate proportion could be explained by potential factors not analyzed in our study. For instance, we did not include factors related to adverse events, such as the frequency of veterinary interventions, which may result in higher avoidance reactions (Waiblinger et al., 2004), nor did we ask farmers if cows' temperament was of importance for the selection of the herd. Another hypothesis is the presence of strong individual differences between cows and between herds, due to variable genetic background or early experience in life.

In conclusion, our study suggests that variations in cow-human relationships are essentially associated with management and the farmer. The housing and milking systems were not found to be associated with this relationship. Our study confirms that variety in human contacts is associated with a lower proportion of fearful cows, and that negative attitudes of caretakers toward cows is associated with higher proportion of cows being afraid of humans; nevertheless, behavioral attitudes did not explain most of the variability between farms. Our study highlights an association between place at calving (isolation from other cows and humans) and humananimal relationships. Nevertheless, the cross-cutting epidemiological approach used in this study does not let us make conclusions on cause-effect relations, but helps to formulate new hypotheses to test in intervention studies or in controlled experiments. Experiments to assess how cows perceive and react to human presence at calving would give insights into their motivation for isolation from humans, and into the short-, middle-, and long-term effects of human presence at calving on cow-human relationships. Similarly, the measure of cows' motivation to feed according to their body condition could be checked in experimental conditions, as already done to study cows' motivation to feed according to milk production (Cooper et al., 2010). The sample of farms was chosen to reflect the diversity of loose-housing dairy farms in France in terms of herd size, breed, location, and so on (Agreste, 2008; French Livestock Institute, 2009). Further studies in large farms with several groups of cows being managed in parallel by different caretakers could bring additional information on the specific contribution of caretakers on human-animal relationships while the environment remains similar for all cow groups. We did not include tied-stall systems because these are less frequent in France (French Livestock Institute, 2009). Further studies that include tied-stall systems are needed, especially in countries where they are still common.

\section{ACKNOWLEDGMENTS}

We thank the Groupements de Défense Sanitaire for lists of eligible farms, all the farmers who freely cooperated in this survey, and Danone Research for financial support. We are also particularly grateful to Maud Coignard (ONIRIS, Ecole Nationale Vétérinaire Agroalimentaire et de l'Alimentation Nantes-Atlantique, Nantes, France), Eric Delval and Christophe Mallet (INRA, Institut National de la Recherche Agronomique, Saint-Genès-Champanelle, France), and Remi Debauchez (ISARA, Institut Supérieur d'Agriculture et d'agroalimentaire Rhône-Alpes, Lyon, France) for their help in data collection; Jean-Yves Audiart and Didier Billon (ONIRIS, Nantes, France) for their help with data entry; and Julie Cat and Céline Faverjon (INRA, Saint-Genès-Champanelle, France) for their advice on statistics. The authors also thank Joop Lensink (ISA, Institut d'enseignement Supérieur spécialisé en Agriculture, Lille, France) for valuable advice on questionnaire design. We also thank ATT (Clermont-Ferrand, France) for language editing. 


\section{REFERENCES}

Agreste. 2008. Enquête bâtiments d'élevage bovins, Principaux résultats sur les exploitations, l'utilisation des déjections, les équipements, les bâtiments fosses et aires. Ministère de l'Agriculture, de l'AgroAlimentaire et de la forêt, Paris, France. http://agreste.agriculture. gouv.fr/enquetes/productions-animales-625/batiments-d-elevagebovin/

Ajzen, I., and M. Fishbein. 1980. Understanding Attitudes and Predicting Social Behaviour. Prentice-Hall Inc., Englewood Cliffs, NJ.

Akaike, H. 1973. Information theory and an extension of the maximum likelihood principle. Pages 267-281 in Proc. Second International Symposium on Information Theory. Akademiai Kiado, Budapest, Hungary.

Boivin, X., J. P. Garel, A. Mante, and P. Le Neindre. 1998. Beef calves react differently to different handlers according to the test situation and their previous interactions with their caretaker. Appl. Anim. Behav. Sci. 55:245-257. http://dx.doi.org/10.1016/S01681591(97)00050-6.

Boivin, X., P. Le Neindre, and J. M. Chupin. 1992. Establishment of cattle-human relationships. Appl. Anim. Behav. Sci. 32:325-335. http://dx.doi.org/10.1016/S0168-1591(05)80025-5.

Boivin, X., P. Le Neindre, J. P. Garel, and J. M. Chupin. 1994. Influence of breed and rearing management on cattle reactions during human handling. Appl. Anim. Behav. Sci. 39:115-122. http:// dx.doi.org/10.1016/0168-1591(94)90131-7.

Breuer, K., P. H. Hemsworth, J. L. Barnett, L. R. Matthews, and G. L. Coleman. 2000. Behavioural response to humans and the productivity of commercial dairy cows. Appl. Anim. Behav. Sci. 66:273-288. http://dx.doi.org/10.1016/S0168-1591(99)00097-0.

Burnham, K. P., D. R. Anderson, and K. P. Huyvaert. 2011. AIC model selection and multimodel inference in behavioral ecology: Some backgrounds, observations, and comparisons. Behav. Ecol. Sociobiol. 65:23-35. http://dx.doi.org/10.1007/s00265-010-1029-6.

Cooper, M. D., D. R. Arney, and C. J. C. Phillips. 2010. The motivation of high- and low-yielding dairy cows to obtain supplementary concentrate feed. Journal of Veterinary Behavior: Clinical Applications and Research 5:75-81. http://dx.doi.org/10.1016/j. jveb.2009.09.045.

Dohoo, I., W. Martin, and H. Stryhn. 2009. Veterinary Epidemiologic Research, 2nd ed. Charlottetown, Canada.

Eagly, A. H., and S. Chaiken. 1993. The psychology of attitudes. Harcourt Brace Jovanovich College Publishers, Orlando, FL.

Edmondson, A. J., I. J. Lean, L. D. Weaver, T. Farver, and G. Webster. 1989. A body condition scoring chart for Holstein dairy cows. J. Dairy Sci. 72:68-78. http://dx.doi.org/10.3168/jds.S00220302(89)79081-0.

European Food Safety Authority. 2009. Scientific report of EFSA prepared by the Animal Health and Animal Welfare Unit (AHAW) on the effect of farming systems on dairy cow welfare and disease. Annex to the EFSA Journal 1143. 284. http://www.efsa.europa. eu/en/efsajournal/doc/1143r.pdf.

French Livestock Institute. 2009. Dairy production in 2015 in France, to an accentuation of regional contrasts. Dossier Economie de l'élevage 391:1-71.

Fukasawa, M. 2012. Calf training for loading onto vehicle at weaning. Animal science journal $=$ Nihon chikusan Gakkaiho 83:759-766. http://dx.doi.org/10.1111/j.1740-0929.2012.01020.x.

Grandin, T. 2010. How to Improve Livestock Handling and Reduce Stress. Improving Animal Welfare, A Practical Approach. CAB International, Wallingford, UK.

Grandin, T., and M. J. Deesing. 1998. Genetics and behavior during handling, restraint and herding. Pages 113-144 in Genetics and the Behavior of Domestic Animals. T. Grandin, ed. Academic Press, London, UK.

Haskell, M. J., G. Simm, and S. P. Turner. 2014. Genetic selection for temperament traits in dairy and beef cattle. Front. Genet. 5. http://dx.doi.org/10.3389/fgene.2014.00368.

Hemsworth, P. H., J. L. Barnett, G. J. Coleman, and C. Hansen. 1989a A study of the relationships between the attitudinal and behavioural profiles of stockpersons and the level of fear of humans and reproductive performance of commercial pigs. Appl. Anim. Behav Sci. 23:301-314. http://dx.doi.org/10.1016/0168-1591(89)90099-3.

Hemsworth, P. H., J. L. Barnett, A. J. Tilbrook, and C. Hansen. 1989b. The effects of handling by humans at calving and during milking on the behaviour and milk cortisol concentrations of primiparous dairy cows. Appl. Anim. Behav. Sci. 22:313-326. http:// dx.doi.org/10.1016/0168-1591(89)90026-9.

Hemsworth, P. H., and X. Boivin. 2011. Human contact. Pages 246262 in Animal Welfare, 2nd ed. M. Appleby, J. Mench, A. Olsson, and B. Hughes, ed. CAB International, Wallingford, UK.

Hemsworth, P. H. and G. J. Coleman. 2010. Human-Livestock Interactions: The Stockperson and the Productivity and Welfare of Intensive Farmed Animals, 2nd ed. CAB International, Wallingford, UK.

Hemsworth, P. H., G. J. Coleman, J. L. Barnett, and S. Borg. 2000. Relationships between human-animal interactions and productivity of commercial dairy cows. J. Anim. Sci. 78:2821-2831.

Hemsworth, P. H., C. Hansen, and J. L. Barnett. 1987. The effects of human presence at the time of calving of primiparous cows on their subsequent behavioural response to milking. Appl. Anim. Behav. Sci. 18:247-255. http://dx.doi.org/10.1016/0168-1591(87)90220-6.

Ivemeyer, S., U. Knierim, and S. Waiblinger. 2011. Effect of human-animal relationship and management on udder health in Swiss dairy herds. J. Dairy Sci. 94:5890-5902. http://dx.doi.org/10.3168/ jds.2010-4048.

Jago, J. G., C. C. Krohn, and L. R. Matthews. 1999. The influence of feeding and handling on the development of the human-animal interactions in young cattle. Appl. Anim. Behav. Sci. 62:137-151. http://dx.doi.org/10.1016/S0168-1591(98)00219-6.

Kallioniemi, M. K., S. M. Raussi, R. H. Rautiainen, and H. R. Kymalainen. 2011. Safety and animal handling practices among women dairy operators. J. Agric. Saf. Health 17:63-78.

Lensink, J., A. Boissy, and I. Veissier. 2000. The relationship between farmers' attitude and behaviour towards calves, and productivity of veal units. Ann. Zootech. 49:313-327. http://dx.doi.org/10.1051/ animres:2000122

Lensink, J., I. Veissier, and L. Florand. 2001. The farmers' influence on calves' behaviour, health and production of a veal unit. Anim. Sci. 72:105-116.

Lidfors, L. M., D. Moran, J. Jung, P. Jensen, and H. Castren. 1994 Behaviour at calving and choice of calving place in cattle kept in different environments. Appl. Anim. Behav. Sci. 42:11-28. http:// dx.doi.org/10.1016/0168-1591(94)90003-5.

Mounier, L., S. Colson, M. Roux, H. Dubroeucq, A. Boissy, S. Ingrand, and I. Veissier. 2006. Links between specialization in the finishing of bulls, mixing, farmers' attitudes towards animals and the production of finishing bulls: a survey on French farms. J. Anim. Sci. 82:561-568.

Mülleder, C., J. Troxler, and S. Waiblinger. 2003. Methodological aspects for the assessment of social behaviour and avoidance distance on dairy farms. Anim. Welf. 12:579-584.

Murphey, R. M., F. M. Duarte, and M. Torres Penedo. 1981. Responses of cattle to humans in open spaces: Breed comparisons and approach-avoidance relationships. Behav. Genet. 11:37-48. http:// dx.doi.org/10.1007/BF01065826.

Murphey, R. M., F. Moura Duarte, and M. Torres Penedo. 1980. Approachability of bovine cattle in pastures: Breed comparisons and a breed $\times$ treatment analysis. Behav. Genet. 10:171-181. http:// dx.doi.org/10.1007/BF01066267.

Probst, J. K., A. Spengler Neff, F. Leiber, M. Kreuzer, and E. Hillmann. 2012. Gentle touching in early life reduces avoidance distance and slaughter stress in beef cattle. Appl. Anim. Behav. Sci 139:42-49. http://dx.doi.org/10.1016/j.applanim.2012.03.002.

Proudfoot, K. L., M. B. Jensen, D. M. Weary, and M. A. G. von Keyserlingk. 2014. Dairy cows seek isolation at calving and when ill. J. Dairy Sci. 97:2731-2739. http://dx.doi.org/10.3168/jds.2013-7274.

$\mathrm{R}$ Development Core Team. 2009. R Version 2.10.1.: A language and environment for statistical computing. R Foundation for Statistical Computing, Vienna, Austria. http://www.R-project.org.

Rushen, J., A. A. Taylor, and A. M. de Passille. 1999. Domestic animals' fear of humans and its effect on their welfare. Appl. 
Anim. Behav. Sci. 65:285-303. http://dx.doi.org/10.1016/S01681591(99)00089-1.

Schütz, K. E., M. Hawke, J. R. Waas, L. M. McLeay, E. A. M. Bokkers, C. G. van Reenen, J. R. Webster, and M. Stewart. 2012. Effects of human handling during early rearing on the behaviour of dairy calves. Anim. Welf. 21:19-26. http://dx.doi. org/10.7120/096272812799129411.

Seabrook, M. F. 1984. The psychological interaction between the stockman and his animals and its influence on performance of pigs and dairy cows. Vet. Rec. 115:84-87. http://dx.doi.org/10.1136/ vr.115.4.84.

Seabrook, M. F. 2001. The effect of the operational environment and operating protocols on the attitudes and behaviour of employed stockpersons. Pages 21-30 in Proc. 3rd NAHWOA Workshop, Human-Animal Relationship: Stockmanship and Housing in Organic Livestock Systems. University of Reading, UK, Clermont-Ferrand, France.

Waiblinger, S., X. Boivin, V. Pedersen, M.-V. Tosi, A. M. Janczak, E. K. Visser, and R. B. Jones. 2006. Assessing the humananimal relationship in farmed species: A critical review. Appl. Anim. Behav. Sci. 101:185-242. http://dx.doi.org/10.1016/j. applanim.2006.02.001.

Waiblinger, S., and C. Menke. 1999. Influence of herd size on human cow relationships. Anthrozoos 12:240-247. http://dx.doi. org/10.2752/089279399787000156.

Waiblinger, S., C. Menke, and G. J. Coleman. 2002. The relationship between attitudes, personal characteristics and behaviour of stock- people and subsequent behaviour and production of dairy cows. Pages 195-219 in Appl. Anim. Behav. Sci. Vol. 79.

Waiblinger, S., C. Menke, and D. W. Fölsch. 2003. Influences on the avoidance and approach behaviour of dairy cows towards humans on 35 farms. Appl. Anim. Behav. Sci. 84:23-39. http://dx.doi. org/10.1016/S0168-1591(03)00148-5.

Waiblinger, S., C. Menke, J. Korff, and A. Bucher. 2004. Previous handling and gentle interactions affect behaviour and heart rate of dairy cows during a veterinary procedure. Appl. Anim. Behav. Sci. 85:31-42. http://dx.doi.org/10.1016/j.applanim.2003.07.002.

Welfare Quality. 2009. Welfare Quality ${ }^{\circledR}$ Assessment Protocol for Cattle. Welfare Quality ${ }^{\circledR}$ Consortium. Lelystad, the Netherlands.

Winckler, C., J. Brinkmann, and J. Glatz. 2007. Long-term consistency of selected animal-related welfare parameters in dairy farms. Anim. Welf. 16:197-199.

Windschnurer, I., C. Schmied, X. Boivin, and S. Waiblinger. 2008 Reliability and inter-test relationship of tests for on-farm assessment of dairy cows' relationship to humans. Appl. Anim. Behav. Sci. 114:37-53. http://dx.doi.org/10.1016/j.applanim.2008.01.017.

Windschnurer, I. C. Schmied, X. Boivin, and S. Waiblinger. 2009. Assessment of human-animal relationships in dairy cows. Pages 137152 in Assessment of Animal Welfare Measures for Dairy Cattle, Beef Bulls and Veal Calves. Welfare Quality ${ }^{\circledR}$ Reports No 11. B. Forkman and L. J. Keeling, ed. Cardiff University, UK. 